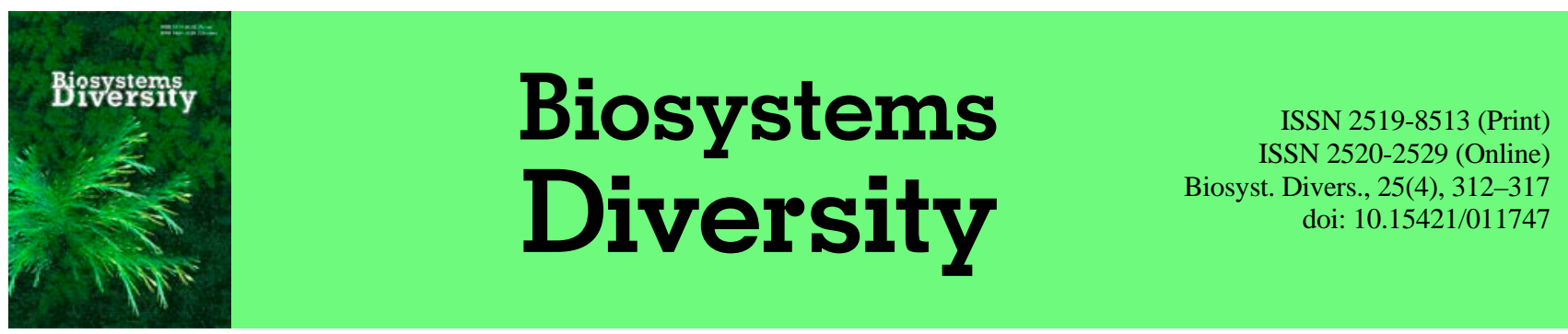

\title{
Lower vertebrates of Sehlabathebe National Park, Lesotho
}

\author{
G. Kopij \\ Wroclaw University of Environmental \& Life Sciences, Wroclaw, Poland \\ University of Namibia, Oshakati, Namibia
}

Article info

Received 19.10.2017

Received in revised form 07.11.2017

Accepted 14.11.2017

Wroclaw University of Environmental \& Life Sciences,

Ul. Kozuchowska, $5 b$,

Wroclaw, 51-531, Poland.

University of Namibia,

Private Bag 5520,

Oshakati, Namibia

E-mail:g.kopij@unam.na
Kopij, G. (2017). Lower vertebrates of Sehlabathebe National Park, Lesotho. Biosystems Diversity, 25(4), 312-317 doi:10.15421/011747

Five snake, four lizard, nine amphibian (all anurans) and three fish species were recorded in the Apline grasslands of the Sehlabathebe National Park, South-Eastern Lesotho, Southern Africa. They include rare, threatened and endemic species, some of which are restricted to the Drakensberg / Maloti region. The following species were recorded: snakes Lamprophis aurora, L. fuscus, Hemachatus haemachatus, Bitis arietans, B. atropos; lizards Trachylepsis punctatissima, Tropidosaura montana, Pseudocordylus melanotus, Afroedura nivaria; amphibians (anurans) Xenopus laevis laevis, Bufo gariepensis nubicolus, Cacosternum striatum, Amietia dracomontana, A. angloensis, A. fuscigula, A. umbraculata, Strongylopus fasciatus, Semnodactylus wealii; fishes Labeobarbus aeneus, Pseudobarbus quathlambae and Oncorhynchus mykiss. Species with high conservation priorities include: Lamprophis fuscus, Tropidosaura cottrelli, Pseudocordylus spinosus, Amietia umbraculata, A. drakomontana, Strongylopus fasciatus and Pseudobarbus quathlambae.

Keywords: reptiles; amphibians; fish; Amietia umbraculata; Pseudobarbus quathlambae; conservation

\section{Introduction}

Southern Africa has a rich and diverse herpetofauna, with 517 currently described reptile species (Alexander and Marais, 2007) and more than 160 amphibian species (du Preez and Carruthers, 2009). While the latter class is represented in this region by a single order Anura, the former includes 151 snake (in 49 genera and seven families), 338 lizard (in 48 genera and nine families) and 27 tortoise (in 14 genera and five families) species (Alexander and Marais, 2007). On the other hand, the ichthyofauna of Southern Africa is relatively poor, with 245 species recorded in the Zambezi Basin and in rivers further south. However, this biodiversity of lower vertebrates mapped insignificantly, and good mapping remains essential for any conservation planning.

In Southern Africa, protected areas play an important role in reptile, amphibian and fish conservatrion, for many representatives of these classes have very restricted ranges and specific habitat requirements (Passmore and Curruthers, 1995; Branch, 1998; Channing, 2001; Skelton, 2001; du Preez and Carruthers 2009). Therefore, the protected areas, especially national parks, may therefore cover significant parts of their range. So far, howerer, little is known on the fauna of lower invertebrates in most of these protected areas. For example Bates $(1996,1997)$ provided a checklist of amphibian and reptile species occurring in all nature reserves and national parks in the Free State province of South Africa. Nevertheless, the neighbouring country, Lesotho, has six nature reserves and one national park (Ambrose et al., 2000), though no information on lower vertebrates for any of these areas was provided so far.

This paper provides a systematic list of fish, amphibian and reptile species ever recorded in Sehlabathebe National Park (SNP) and some background information on the occurrence of these species in Lesotho and in Southern Africa in general (based mainly on Bates et al. (2014)). This paper therefore supplements previously published checklists on higher vertebrates in this park, viz. mammals (Lynch and Watson, 1990; Kopij, 2006a) and birds (Kopij, 2002).

\section{Study area}

Sehlabathebe National Park (SNP), is situated in the Qacha's

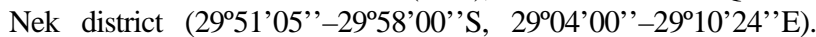
It is 7,239 ha in extent and consists of Cave Sandstone plateaux ranging in elevation from 2,300 to 2,500 $\mathrm{m}$ a. s. 1 . This is therefore the highest known altitude at which Cave Sandstone occurs in Southern Africa (Schmitz and Rooyani, 1987). Where the Cave Sandstone protrudes, it has been eroded into caves, prominent shapes and rock pools. Volcanic dykes intrude into the Sandstone Cave in some places. The soil in SNP is partly sedimentary from the Sandstone Cave and partly lithosol from the volcanic rocks (Kopij and Hoener, in prep.; Schmitz and Rooyani, 1987).

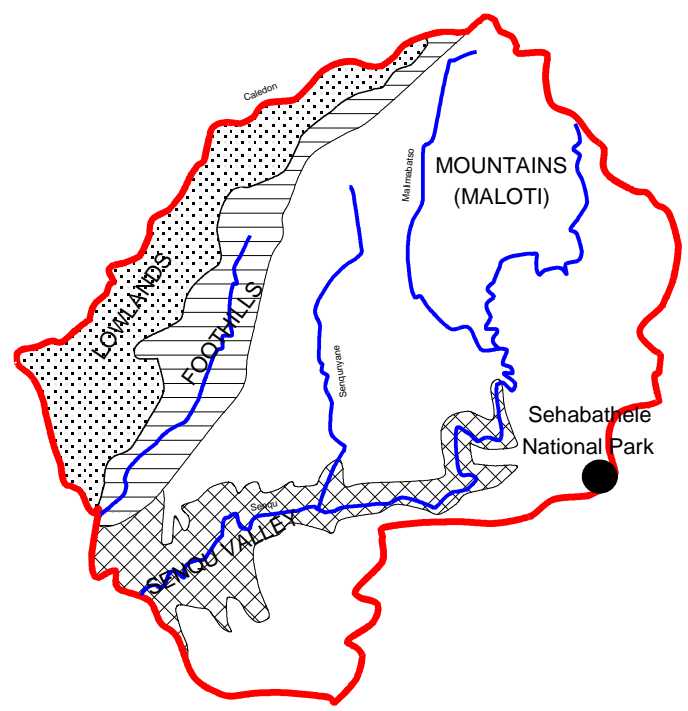

Fig. 1. Map of Lesotho showing location of Sehlabathebe Natonal Park 


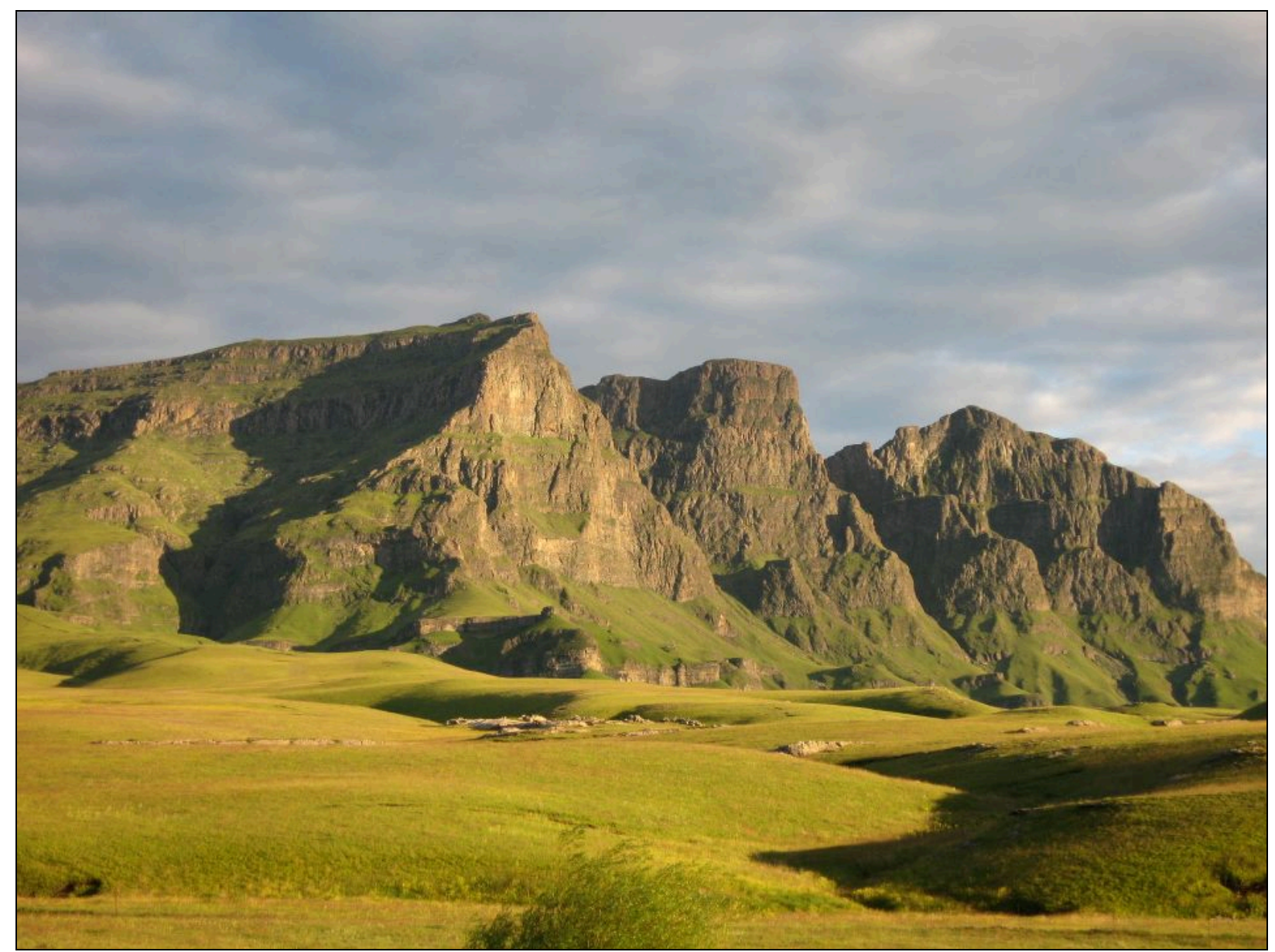

Fig. 2. A general view of Sehlabathebe National Park

The water resources of SNP can be divided into: a) rivers, streams and their tributaries; b) oxbow ponds; c) marshes and bogs; d) rock pools; e) man-made dams. The park consists of two watersheds: the Leqooa River and the Tsoelikane River. The Leqooa flows from the north to the south through the Sehlabathebe Valley. The Tsoelikane has its headwaters in SNP and near Moshebi it merges to form the Tsoelke River, which empties into the Senqu near Qacha's Nek.

The Tsoelikane flows in a SW direction and descends from 2,410 m to 2,220 m a. s. l. on its $12 \mathrm{~km}$ course through the Park. Its overall pattern is dendritic forming numerous valleys and canyons. The Tsoelikane Valley is a mature alluvial flood plain, marked by numerous meanders and oxbow ponds. Many tributaries of both the Tsoelikane and Leqooa contain water only during the wet season.

Associated with the sandstone outcroppings in SNP are the rock pools, which contain rainwater. While a few of these pools are quite large (up to $5 \mathrm{~m}$ deep and $10 \mathrm{~m}$ in diameter), the majority are of much smaller size. The larger rock pools are concentrated in several places. The highest concentration is located at the NE edge of the Park near the lodge.

The vegetation of SNP falls entirely within the Alpine grassland biome (Low and Rebelo, 1996). The grassy areas consist of three vegetation units: Themeda grassland, Themeda-Stiburus grassland, and Pentaschistis grassland (Kopij and Hoener, in prep.). There occur also three types of wetlands within SNP: so called tarns (depressions in the Sandstone Cave filled with water, with very spase emergent vegetation), riparian marshes and inland freshwater marshes (Schwabe, 1990).

During the years 1970-1974, eight dams were built near the headwaters of the Tsoelikane. All of them were formed by excavation of stream valleys and construction of earthen dams. Four of the reservoirs, representing a waterway chain of impoundments, were built near the lodge, and one dam, which today constitutes a marshland, was built c. $6 \mathrm{~km} \mathrm{~S}$ of the lodge. As the dams are continually flushed by new supplies of fresh, stream water, the water of these reservoirs is usually clear and relatively cold. Most of the dams were built to provide a habitat which would support trout fishing. All the dams serve also as wildlife habitat.

A total of 597 different species and sub-species of vascular plants represented by 74 families and 271 genera have been recorded in SNP (Kopij and Hoener, in press). Although systematic lists have been completed for mammals (Lynch and Watson, 1990) and birds (Kopij, 2002) for the park, to date no such list has been available for lower vertebrates.

The climate of SNP is a composition of the climate effecting Lesotho and Natal Drakensberg as a whole. While the main Lesotho climatological pattenr flows across the highlands in a SE direction, that from KwaZulu-Natal often flows in a W direction, bringing moist and subtropical air currents inland from the Indian Ocean. In fact, the seemingly dynamic and unpredictable weather which characterize SNP can be viewed as the product of the forces of these two main climatological patterns mixing and collecting the Drakensberg interface. During must of summer, the dynamic and unpredictable weather is often exemplified by the following sequence of weather patterns, all occurring from sunrise to sunset: dense mist from the east; a light, easterly wind and clear sky; increasing cloud cover; a thunderstorm approaching from the east; heavy rain; a cold front from the west associated with snow; clearing sky; dense mist from the Drakensbeg Escarpment.

\section{Systematic review of species}

Information on the status of species of lower vertebrates within SNP are based both on published and unpublished records. The paper provides the status of species in Lesotho (based mainly on unpublished data) and conservation status in South Africa (based on Branch, 1988; Minter et al., 2004; Bates et al., 2014). The nomenclature, taxonomy, 
common names and descriptions of reptiles in the article are given according to Branch (1998) Alexander and Marais (2007) and Bates et al. (2014); amphibians - Passmore and Carruthers (1995), Channing (2001), Bates and Haacke (2003), Minter et al. (2004), and du Preez and Carruthers (2009); and fish - Skelton (2001).

The taxonomy of reptiles and amphibians in Southern Africa is in a state of flux (cf. Passmore and Carruthers (1995) with du Preez and Carruthers (2009), or Branch (1988) with Alexander and Marais (2007)). All Afrotropical skinks formerly referred to the genus Mabuya (Branch, 1998; Broadly, 2000) are now referable to Trachylepis (Bauer, 2003). Although the genera Pseudocordylus and Chamaesura have been transferred to the genus Cordylus by Frost et al. (2001), the name Pseudocordylus for crag lizards is still recommended to be used until a more comprehensive molecular analysis has been conducted (le F. Mounton, B. Branch). The former name of the Giant River Frog, Rana vertebralis, has been changed to Amietia vertebralis (Bates, 2002), while all other South African species of the genus Rana were referred to Afrana (Visser and Channing, 1997; Channing, 2001; Minter et al., 2004) and soon after to Amietia (du Preez and Carruthers, 2009). The systematics is not stable even on the family level, e.g. all the Amietia species were for a long time placed in the family Ranidae, and now the genus is placed in the family Pyxicephalidae. Wheever appropriate, remarks on taxonomic status of species are also provided.

\section{Reptiles \\ Snakes}

\section{Colubridae}

Typical snakes, mostly terrestrial, rock-dwelling or aquatic, non-venomous. They have nine enlarged scales on the top of the head and well-developed eyes. There are 27 genera and 78 species in Southern Africa.

Aurora House Snake Lamprophis aurora (Linnaeus, 1758). It is a shiny olive-green snake, with an orange stripe along the rosnal part of the body; $45-60 \mathrm{~cm}$ in length. It is a shy, nocturnal and elusive species, associated with damp localities in open grasslands. Its main prey includes lizards, frogs and small rodents. It is a non-venomous snake which kills its prey by constriction. To date, there is only one record of this species from SNP (O. Borquin). The Aurora Snake is fairly common in Lesotho lowlands, but rare in the Maloti. It is endemic to South Africa and Lesotho, and declining all over its range.
Yellow-bellied House Snake Lamprophis fuscus Boulenger, 1893. Pale brown, with characteristic yellow lips, sides and belly. Adults range from 40 to $50 \mathrm{~cm}$. Preys include lizards and small rodents. Branch (1998) maps this species for SNP, but the original record have not been found (Ambrose, 2001b). Also Broadley (1990) does not plot any record of this species in Lesotho. The Yellow-bellied House Snake is, therefore, not a definite record for Lesotho. It is endemic to eastern South Africa and Lesotho.

\section{Elapidae}

The cobras and related species are slender and agile snakes. Most of them are highly venomous. Oviparous. There are 16 species in six genera in Southern Africa.

Rinkhals Hemachatus haemachatus (Lacépède, 1788). It is a cobra-like snake, dark brown, usually 1.0-1.5 m long. Specimens from Lesotho are often banded (G. Kopij). It has keeled, not polished dorsal scales, which is an exception among Southern African elapids. The most characteristic trait of the snake is the presence of 1-4 white crossbars on the throat, especially well-visible in its cobra-like defensive posture. It hunts a wide range of prey. It is deadly poisonous and can spit the venom into one's eyes. Unlike cobras it is viviparous, 20-30 young are born each year. The Rinkhals prefer open grasslands. A specimen from SNP is deposited in the Natal Parks Board Collection (O. Bourquin). It was found both in the lowlands and highlands of Lesotho (G. Kopij). It is endemic to South Africa and Lesotho.

\section{Viperidae}

They are short and heavily built snakes, with a broad triangular head. The scalation on the top of the head is very fragmented. All species are slow-moving, sluggish, but very venomous. Most species are terrestrial or subfossorial. Three genera and 15 species occur in Southern Africa.

Puff Adder Bitis arietans (Merrem, 1820). It is brownish, with shades of black and yellow, reaching $1 \mathrm{~m}$ in length. Two dark stripes run on the sides of the head, one above the eye and one below it. The Puff Adder preys mainly on rodents. It is viviparous, 20-40 young are born in late summer. It is fairly common in SNP and can be encountered mainly on mountain tops. It has been recorded throughout Lesotho highlands and foothills. It is, in fact, ones of the most widespread and commonest snakes in Southern Africa.

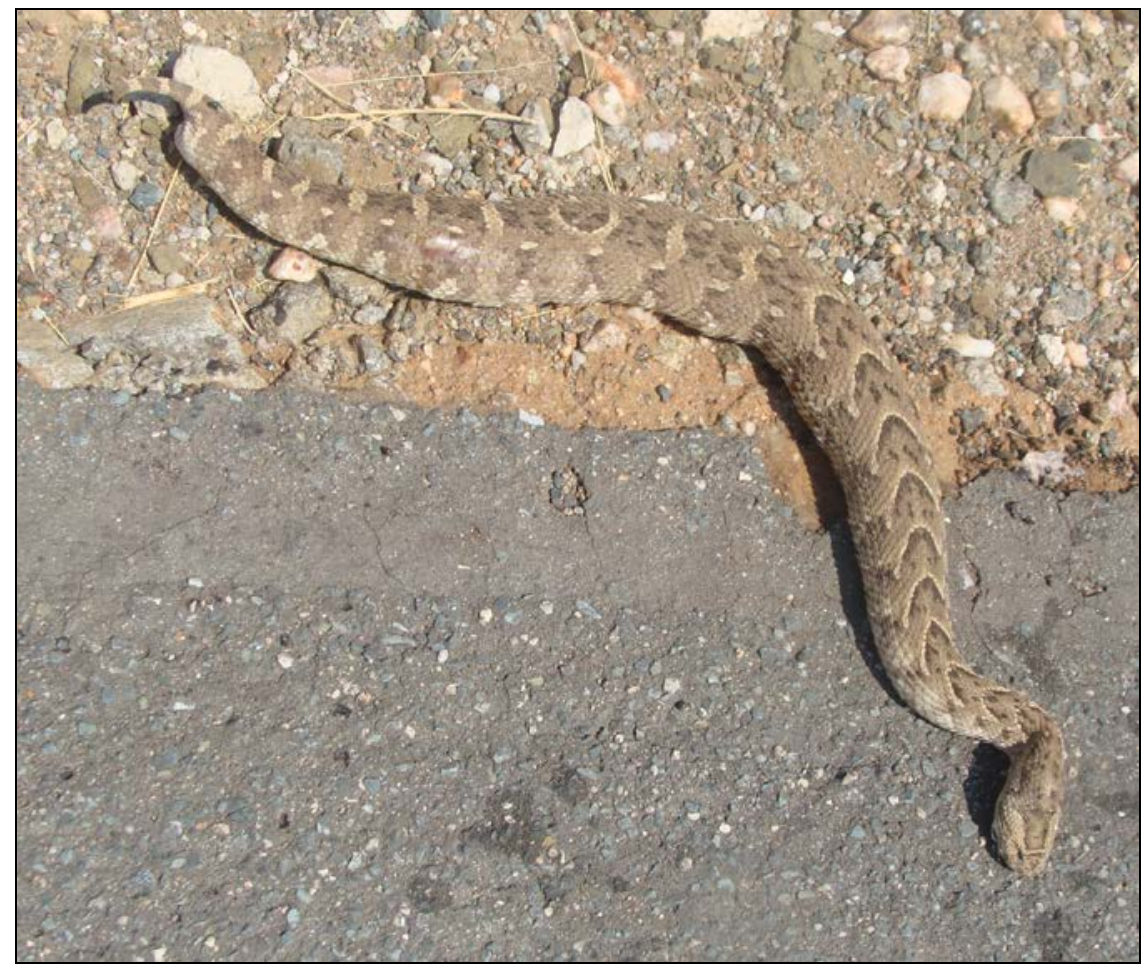

Fig. 3. The Puff Adder 


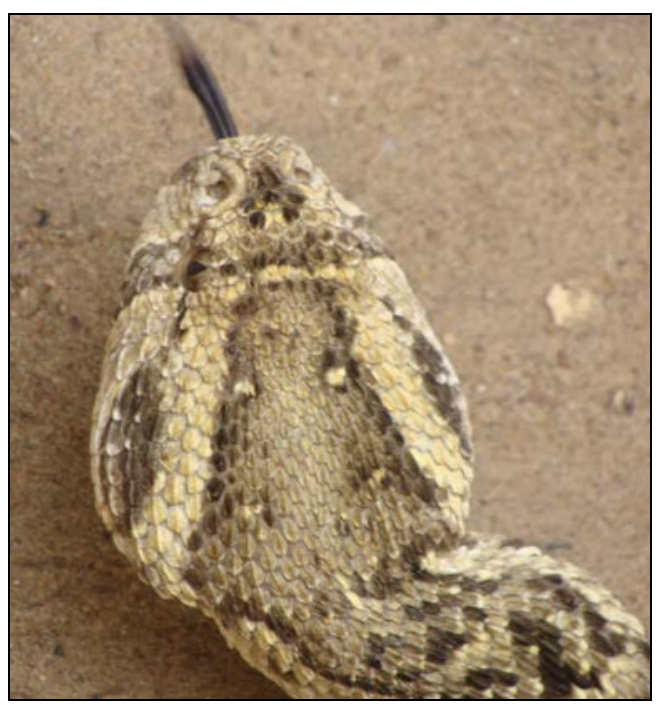

Fig. 4. The head of the Puff Adder

Berg Adder Bitis atropos (Linnaeus, 1758). A small snake (30-40 cm), with characteristic dark arrow mark on the top of the head, flanked with white stripes. Usually it is seen in grass tussocks on rocky ledges. It preys mainly on small rodents and lizards. Viviparous, litter size ranges form 4 to 16 young. It prefers cold and high rainfall areas, therefore the SNP constitutes its optimal habitat, where it is the commonest snake species. It occurs also in Western Cape, Mpumalanga, Limpopo and Manicaland.

Lizards

\section{Scincidae}

The cylindrical body is covered with small, tight shiny scales. The head is not distinct from the neck. Terrestrial or fossorial. The second to Geckonidae most speciose reptile family in Southern Africa (10 genera, 74 species).

Montane Speckled Skink Trachylepsis punctatissima (Peters, 1844). The former name of this species was Mabuya striata (Peters, 1844). All its subspecies were recently elevated by Broadley (2000) to the rank of separate species and the former subspecies M. s. punctatissima recorded in SNP is now named Trachylepsis punctatissima. It is usually associated with rocky outcrops and barren lands. It was recorded from few sites in SNP. It is widespread all over the Maloti (own observ.). The Montane Speckled Skink is endemic to sout-eastern South Africa and Lesotho.

\section{Lacertidae}

They have small, granular dorsal scales, and large rectangular ventral scales arranged in longitudinal rows. Terrestrial, oviparous. The southern Africa includes a total of 37 species in arranged in six genera.

Common Mountain Lizard Tropidosaura montana (Duméril et Bibron, 1839). A brownish lizard with diffuse stripes on the dorsal part of the body. The belly is bluish. It has rough small scales on the back and large scales on the head. Body length: 52-66 mm. Oviparous, litter size: 2-8 eggs. Very little known species, endemic to South Africa. A specimen probably belonging to this species was collected in SNP (O. Bourquin). If so, this would constitute the only record for Lesotho (Ambrose, 2001). However, we should mention that some authors mention T. montana and T. essexi as one species. The species at SNP may be either (if the former than the subspecies T. m. rangeri; Branch, 1998), or both species may occur there.

\section{Cordylidae}

Robust lizards, slightly compressed laterally, with a large distinctive head. The top of the head is covered with dermal bony plates. The tail has whorls of keeled scales. Most species are rockdwellers, diurnal and viviparous. Four genera and 53 species occur in Southern Africa.

Drakensberg Crag Lizard Pseudocordylus melanotus subviridis (Smith, 1838). A large lizard, 70-150 mm in length. Greyish above and greenish and orange on the sides and belly. In SNP often was seen in rocks or on the small walls on roadsides and in several other sites, where they often live in aggregations. They are heliothermic, feeding on millipedes, grasshoppers, beetles and other arthropods. It appears to be the most common lizard in SNP. It was recorded throughout the Maloti, but is absent in the Lesotho's lowlands (G. Kopij). Endemic to South Africa and Lesotho.

\section{Geckonidae}

They are covered with minute scales only on the head. Prominently big eyes covered with transparent skin, which are cleaned with tongue. They have pads on their digits that adhere strongly even to very smooth surface. It is the most speciose reptile family in southern Africa (15 genera and 111 species).

Mountain Flat Gecko Afroedura nivaria (Boulenger, 1894). It is a beige in colouration, with irregular brown blotches. The body is flat, allowing an easy access to narrow crevices in rocks. The tail is thick at the base, easily shed. Toes are clawless. It is nocturnal, preying on small arthropods. Like all other geckos, it always lays only two eggs. Although Bates and Bauer (2014) did not record this species in Lesotho, a specimen from Sehlabathebe is held in the Natal Parks Board Collection (O. Bourquin). Highly habitat-specific, occupying overhangs in the sandstone cliffs of the Clarens Formation. Endemic to South Africa and Lesotho. It has also been recorded in the eastern Free State, e. g. Golden Gate Highlands National Park, Korannaberg and Platberg, and in Natal Drakensberg (Bates, 1996; Bates and Bauer, 2014).

\section{Amphibians (Anura)}

Pipidae

Streamlined, smooth, highly aquatic frogs. They possess large webbed feet and outstanding sensory organ on the body sides. There are six species of a single genus in southern Africa.

Common Platana Xenopus laevis laevis (Daudin, 1802). A large frog up to $147 \mathrm{~mm}$, brown with lighter blotches above and whitish below; slimy skin surface; snout rounded, eyes face dorsally. It feeds on insects, small fish and their own tadpoles. They themselves are heavy preyed upon by numerous water bird species (Kopij et al., 2004; Kopij, 2006b). It is one of the most aquatic anuran in southern Africa, and one of the most tolerant of water pollution. The Common Platana is fairly common in SNP. It is often encountered in small water bodies both artificial and natural. It is a common and widespread species throughout Lesotho (G. Kopij), as well as in other African countries south of Sahara.

\section{Bufonidae}

Toads are characterized by thick and warty skin and large parotid glands behind eyes, which secrete an irritant to detect predators. Four genera and 26 species ( 23 of them in the genus Bufo) were recorded in southern Africa.

Karoo Toad Bufo gariepensis nubicolus Hewitt, 1927. It is robust and relatively large toad ( $95 \mathrm{~mm}$ ), usually olive-brown, with darker irregular patches. It has large and conspicuous parotoid glands. It preys on small arthropods. It inhabits grasslands, usually close to water bodies. It breeds in swampy areas and is tolerant of low temperature. There is a specimen from SNP in the Natal Parks Board Collection (O. Bourquin). The Karoo Toad is endemic to South Africa and Lesotho. In the rest of the country, it is restricted to Maloti, on the eastern and the northern border (Bates and Haacke, 2003).

\section{Pyxicephalidae}

Large, common and widespread aquatic or semi-aquatic frogs. The pupil in the eye is horizontal. It is the most speciose amphibian family in Southern Africa: nine genera and 47 species. The genus Amietia includes seven species in this region. Formerly most species which belong to Pyxicephalidae were placed in the Ranidae family.

Striped Caco Cacosternum striatum FitzSimons, 1947. It is a small (21 mm), light brown frog, with a pair of lateral stripes. The belly is whitish. It inhabits moist grasslands. There is a specimen from SNP in the Natal Parks Board Collection (O. Bourquin) and this is constitutes the only record of this species in Lesotho. It is very rare in Southern KwaZulu Natal and Maluti. However, the sibling species, Cacosternum boettgeri is common and widespread 
all over southern Africa, including Lesotho lowlands, but does not occur in Maloti (G. Kopij).

Maluti River Frog Amietia umbraculata (Bush, 1952) = Amietia vertebralis (Hewitt, 1928). The Maluti River Frog (Aquatic River Frog, Umbraculate Frog, Giant River Frog, and Large-mouth Frog Water Rana) is a species with a long history of confusing and ever changing taxonomy and nomenclature, both English and Latin. Originally described as Rana vertebralis (Hewitt, 1927), it soon became Rana umbraculata (Bush, 1952). Later it was placed in a new genus, so the name was changed again to Amietia vertebralis, only to be changed again after some time to Afrana vertebralis (e.g. Minter et al., 2004), and a few years later, again to Amietia umbraculata (e.g. du Preez and Carruthers, 2009). It is a large (150 mm) dark brown frog with a very wide gape and rounded snout. It has large eyes with a prominent umbraculum. It inhabits permanently cold mountain streams and rivers. It preys mainly on invertebrates, including crabs. It is common in the Tsoelikane River in SNP and also most probably also in some of its tributaries. The Maluti River Frog was recorded throughout the Maloti, both in large and small rivers and even in small streams (Bates, 2002). It occurs also in rivers and streams in the foothills of Maloti (G. Kopij). It is endemic to the Drakensberg / Maloti region and was listed in South African Red Data Book as 'Restricted' (Branch, 1988). However, now it is considered not threatened (Minter et al. 2004).

Drakensberg River Frog Amietia dracomontana Channing, 1978. The body is streamlined with a narrow head. Light brown above with dark blotches. Total body length equals $65 \mathrm{~mm}$. Two phalanges of the longest toe are free of webbing, which distinguish it from the sibling species, A. umbraculata. Formerly, it was placed in the genus Rana and Afrana. The main prey includes insects such as beetles and bugs. It lives in permanent mountain streams, $2000 \mathrm{~m}$ a.s.l. In SNP, the frog inhabits the Tsoelikane River and some of its tributaries, beeing quite commonin those areas. The Drakensberg River Frog is endemic to Maloti / Drankensberg region. It was listed as restricted in South African Red Data Book (Branch, 1988), but now is considered as not threatened (Minter et al., 2004).

Common River Frog Amietia angloensis Bocage, 1866. A stream-lined frog, with a pointed snout. It is green above with black blotches; the belly is whitish. Maximum body length is $90 \mathrm{~mm}$. Very similar to A. dracomontana, but two phalanges of the longest toe are not webbed. Like the previous species, it was placed in the genus Rana and later in Afrana. It is associated with all sorts of water bodies, both natural and artificial. It is the commonest frog in SNP, especially often seen in the rock pools. The Common River Frog was recorded throughout Lesotho lowlands and highlands (G. Kopij). It is actually common and widespread all over Africa south of Sahara.

Cape River Frog Amietia fuscigula Duméril et Bibron, 1841. Large (125 mm), robust, with slightly rounded snout, light to dark brown above with various blotches and bands. One phalanx of the longest toe is free of webbing. It inhabits streams and other permanent water bodies amidst grasslands. It preys on insects, millipedes, centipedes and small crabs. Formerly placed in the genus Rana and later in Afrana. It was recorded in SNP by Bates and Haacke (2003). It is restricted to South Africa, Southern Namibia (Fish River) and Lesotho.

Striped Stream Frog Strongylopus fasciatus (Smith, 1849). It is slender with acutely pointed snout, up to $50 \mathrm{~mm}$ long. Light yellowish above with two black dorsal stripes and two shorter black stripes on the body side. The underside is yellowish. Webbing is reduced. It preys on small arthropods. The Striped Stream Frog occurs in grass close to water bodies. There is a specimen from SNP in the Natal Parks Board Collection (O. Bourquin). So far, this is the only record of this elusive species in Lesotho. The range of this species is restricted to South Africa and Zimbabwe.

\section{Hyperoliidae}

Reed frogs are small, agile, often brightly coloured. They are adapted to climb in vegetation such as reeds, bananas and other. Six genera and 26 species were found in southern Africa.

Rattling Frog Semnodactylus wealii (Boulenger, 1882). It is yellowish above, with black longitudinal bands. The belly is whitish and granular. Up to $44 \mathrm{~mm}$ long. Hands and feet are yellowish underside and banded above. It occurs in standing small water bodies, vegetated with sedges and other plants. It utters a characteristic rattling call. A specimen collected in SNP is included in the Natal Parks Board Collection (O. Bourquin). For a long time, it was known in Lesotho only from this park, but recently it was discovered that the species occurs all over the country (Bates and Haacke 2003; Ambrose, 2004).

Fish

\section{Cyprinidae}

Diverse group of fish without teeth and stomach. They possess outstanding hearing organ called Weberian Organ. It is the largest fish family in the world, with seven genera and 80 species in southern Africa.

Smallmouth Yellowfish Labeobarbus aeneus (Burchell, 1822). Olive-brown above and whitish below, attaining $50 \mathrm{~cm}$ in length (7.8 kg). It has characteristically coloured orange fins. Formerly, it was known as Barbus hulubi, later changed to Barbus aeneus. It ihabits clean waters of large rivers, being most common in mountain rivers. The main food consist algae, detritus and benthic invertebrates. In SNP, this fish was recorded as a common species in the Tsoelikane River (Pike and Tedder, 1973). In Lesotho it is abundant in some larger rivers of the Maloti, e.g. Senqunyane, Malibamatso and Bokong (Rall and Steyn, 1996; Rall and Rall, 1999). The Smallmouth Yellowfish is restricted to the Orange River drainage basin.

Maloti Minnow Pseudobarbus quathlambae (Barnard, 1938). Slender, small fish (130 mm in length), grey-brown above and whitish below and characteristic reddish fin bases. It has single pair of short barbles. Males have small granules on the head. This species was first discovered and described by Barnard (1938) among the specimens taken from the upper Umkomazana River in the KwaZulu-Natal Drakensberg. Subsequently, it was thought to have gone extinct, until its re-discovery in the Tsoelikane River in SNP in 1970 (Jubb, 1971; Pike and Tedder, 1973). The species inhabits pools and sheltered parts of mountain rocky streams with clear water. Because of its extremely limited distribution, it has been included in the Red Data Book as an endangered species (Skelton, 1987). Its presence in SNP is of great significance, as apparently it is the only protected area within the range of this species. Studies carried out in 1975 found that the Maloti Minnow is limited within this park to the mainstream area of the Tsoelikane River stretching $7 \mathrm{~km}$ below the waterfall. In 1976 several individuals were introduced into the river above the waterfall. These introduced individuals survived and presumably reproduce there as indicated by the fact that specimens were found in the upper Tsoelikane River. Sehlabathebe National Park, on the Tsoelikana River, has been created for this species. Unfortunately a lodge and trout ponds were built in the upper catchment area. The dams were poorly constructed and this has resulted in siltation in this prime habitat of Maluti Minnow (Cambry, 1996). It is relatively abundant in the Senqunyane, Jordane and Bokoaneng, with an estimated population of 3300 (Rall et al., 1993). Several of these populations are threatened by the Lesotho Highlands Water Project.

\section{Salmonidae}

Slender, relatively large and agile fish, which have single row of sharp teeth in mouth. They possess characteristic adipose fin on the back. They are anadromous predators. Introduced in many parts of the world, also in southern Africa.

Rainbow Trout Oncorhynchus mykiss Walbaum, 1792. Slim and agile fish attaining $660 \mathrm{~mm}$ (4.2 kg in Lesotho). Yellowish above with black dots and distinctive pink lateral band running from the head to the tail. The Rainbow Trout is an introduced species. Its natural range is the rivers of the Western Nearctic region (Skelton, 1993). It inhabits cool, clear and well-oxygenated waters of mountain rivers and streams. It preys on a wide range of invertebrates. The first stocking of a Lesotho river was at Sehlabathebe by Macmillan in the 1940's (Ambrose, 1999). In SNP, they occur in the middle and lower Tsoelikane River below the waterfall and in some man-made dams around the lodge and rock pools. Trout fishing provides one of the major recreational activities in the park 
and its vicinity. The largest specimen (4.15 kg) from SNP was caught in the Leqooa River on 7 January 1967. At that time, it was the second heaviest Rainbow Trout recorded in southern Africa (Ortlepp, 1972). It occurs in most rivers of the Maloti and in Phuthiatsana and Makhaleng (Ambrose, 2006). It is listed as one of eight most invasive fish species in the world, displacing indigenous species by competition and predation (Cambry, 2003).

\section{Conclusions}

Only three fish species were recorded at SNP (21\% of 14 species known from Lesotho; Ambrose (2006a)); nine amphibian species (39\% of 23 Lesotho species; Ambrose (2004)), and nine reptile species (22.0\% of 41 Lesotho species; Ambrose (2006b)). However, several other fish, frog and reptile species may occur within SNP or its close vicinity: Leptotyphlops scutifrons (Broadley, 1990), Lycodonomorphuus rufulus (Broadley, 1990), Lamprophis fuliginosus (Broadley, 1990), Psammophylax rhombeatus (Broadley, 1990), Amphlophrinus multimaculatus (Branch, 1998), Montaspis gilvomaculata (Branch, 1998), Tropisosaura cottrelli (Branch, 1998), Cordylus spinosus (Branch, 1998), Agama atra (Branch, 1998); Bufo gutturalis (Passmore, Carruthers, 1995), B. rangeri (Passmore, Carruthers, 1995), Phrynobatrachus natalensis (Passmore, Carruthers, 1995), Strongylopus hymenopus (Passmore, Carruthers, 1995). Even so, the diversity of lower vertebrates in SNP is rather low compared to mammals (Lynch and Watson, 1990) and birds (Kopij, 2002). The herpetofauna is much poorer even in comparison with urbanized habitats in Bloemfontein, also located in the Highveld Grassland. Kopij and Bates (1997) recorded 49 reptile there (among others 4 tortoise, 4 gecko, 6 skink, and 22 snake species) and nine anuran species. Among the factors, which limit the species diversity of reptiles and amphibians in SNP, the following seem to play an important role: high altitude (2300-2500 $\mathrm{m})$, moist conditions (770 mm of rainfall per annum), very cold and long winters, frequent and heavy snowfalls, low annual minimum temperatures $\left(2.2^{\circ} \mathrm{C}\right)$, relatively uniform topographic relief and habitat diversity (Lynch and Watson, 1990).

Although relatively few species of lower vertebrates occur in SNP, the protected area contains species which are listed in the South African Red Data Book: Amietia umbraculata (restricted) and Pseudobarbus quathlambae (endangered). Three species found in SNP are endemic to the Drakensberg / Maloti region, Amietia umbraculata, Strongylopus fasciatus, Pseudobarbus quathlambae. Sehlabathebe National Park is the only protected area within the Maloti Minnow’s range, and therefore is essential for protecting these endemics.

\section{References}

Alexander, G., \& Marais, J. A. (2007). Guide to reptiles of Southern Africa. Struik Nature, Cape Town.

Ambrose, D. (2004). Lesotho annotated bibliography. Sec. 165: Amphibians, including annotated species checklist. 3rd ed. National University of Lesotho, Roma (Lesotho).

Ambrose, D. (2006a). Lesotho annotated bibliography. Sec. 164: Fish, including annotated species checklist. 2nd ed. National University of Lesotho, Roma (Lesotho).

Ambrose, D. (2006b). Lesotho annotated bibliography. Sec. 166: Reptiles, including annotated species checklist. 3rd ed. National University of Lesotho, Roma (Lesotho).

Ambrose, D., Talukdar, S., \& Pomela, E. M. (2000). Biological diversity in Lesotho. A country study. National Environment Secretariat, Maseru.

Bauer, A. M. (2003). On the identity of Lacerta punctata Linnaeus 1758, the type species of the genus Euprepis Wagler 1830, and the generic assignment of Afro-Malagasy skinks. African Journal of Herpetology, 52(1), 1-7.

Barnard, K. H. (1938). A new species of fresh water fish from Natal. Annales of Natal Museum, 8, 525-528.

Bates, M. F. (1996). New reptile distribution records for the Free State province of South Africa. Navorsinge van die Nasional Museum, Bloemfontein, 12, 1-47.

Bates, M. F. (1997). Herpetofauna of the nature reserves and national parks of the Free State province of South Africa. African Journal of Herpetology, 46, 13-29.
Bates, M. F. (2002). The distribution of Amietia vertebralis (Hewitt 1927) (Anura: Ranidae), with comments on its taxonomic and conservation status. Navorsinge van die Nasional Museum, Bloemfontein, 18, 77-94.

Bates, M. F., Branch, W. R., Bauer, A. M., Burger, M., Marais, J., Alexander, G. J., \& de Villiers, M. S. (Eds.). (2014). Atlas and Red List of the reptiles of South Africa, Lesotho and Swaziland. Suricata 1. SANBI, Pretoria.

Bates, M. F., \& Haacke, W. D. (2003). The frogs of Lesotho: Diversity and distribution. Navorsinge van die Nasional Museum, Bloemfontein, 19, 101-158.

Bourquin, O. (1989). Vertebrate fauna (excluding fish) of eastern Lesotho. Drakensberg/Maloti mountain catchment conservation program: Faunal assessment project: Document 8. Natal Parks Board, Pietermaritzburg.

Branch, W. R. (Ed.). (1988). South African Red Data book - reptiles and amphibians. CSIR, Pretoria.

Branch, B. (1998). Field guide to snakes and other reptiles of Southem Africa. Struik Publishers, Cape Town.

Broadley, D. G. (1990). Fitzsimons' snakes of Southern Africa. Jonathan Ball and Ad. Donker Publishers, Parklands.

Broadley, D. H. (2000). A review of the genus Mabuya in Southeastern Africa (Sauria: Scincidae). African Journal of Herpetology, 49, 87-110.

Cambray, J. A. (1996). Threatened fishes of the world: Pseudobarbus quathlabae (Barnard 1838) (Cyprinidae). Environmental Biology of Fishes, 46, 308.

Cambry, J. A. (2003). Impact of indigenous species diversity caused by the globalisation of alien recreational freshwater species. Hydrobiologia, 500, 217-230.

Channing, A. (2001). Amphibians of Central and Southern Africa. Comell University Press, Ithaca and London.

du Preez, L., \& Carruthers, V. (2009). A complete guide to the frogs of Southern Africa. Struik Nature, Cape Town.

Frost, D., Janies, D., Mouton, P., Le, F N., \& Titus, T. (2001). A moleular perspective on the phylogeny of the girdled lizards (Cordylidae, Squamata). American Museum Novitiates, 3310, 1-10.

Jubb, R. A. (1971). Oreodaimon quathlambae (Labeo quathlambae Barnard) in the Tsoelikane River, South-East Lesotho. Piscator, 81, 39-42.

Kopij, G. (2002). The birds of Sehlabathebe National Park, Lesotho. Koedoe, 45, 65-78.

Kopij, G. (2006a). The grey rhebok Pelea capreolus in Sehlabathebe National Park. African Journal of Ecology, 44, 277-278.

Kopij, G. (2006b). Avian predation of the common platanna, Xenopus laevis. African Herp News, 39, 2-4.

Kopij, G., \& Bates, M. F. (1997). Reptiles and amphibians of Bloemfontein. Kovshaan (Bloemfontein), 17, 17-23.

Kopij, G., Nuttall, R. J., \& de Swardt, D. H. (2004). An analysis of avian (Aves) stomach contents from South Africa. Durban Museum Novitates 29, 21-30.

Low, A. B., \& Rebelo, A. G. (1996). Vegetation of South Africa, Lesotho and Swaziland. Department of Environment Affairs and Tourism, Pretoria.

Lynch, C. D., \& Watson, J. P. (1990). The mammals of Sehlabathebe National Park. Navorsinge van die Nasional Museum, Bloemfontein, 6(12), 523-554.

Minter, L. R., Burger, M., Harrison, J. A., Braack, H. H., Bishop, P. J., \& Kloepfer, D. (Eds.). (2004). Atlas and Red Data Book of frogs of South Africa, Lesotho and Swaziland. SI/MAM Series No 9. Smithsonian Institution, Washington.

Ortlepp, W. D. (1972). A record of a large rainbow from Sehlabathebe, Lesotho. Piscator, 85, 78-79.

Passmore, N. I., \& Carruthers, V. C. (1995). South African frogs. A complete guide. Southem Book Publishers, Halfwayhouse.

Pike, T., \& Tedder, A. J. (1973). Rediscovery of Oreodaimon quathlambae (Bernard). Lammergeyer, 19, 9-15.

Rall, J., \& Rall, V. (1999). Fish. In: Biological monitoring in Lesotho Highlands Water Project. Contract 615. Phase 1A, 1998 monitoring report. AfriDev Consultans, Darling (SA).

Rall, J., \& Steyn, G. (1996). Fish. In: Lesotho highlands water project final report. Contract 1008. Baseline biology survey and reserve development; Phase 1B. Vol. 6: downstream studies. AfriDev Consultans, Darling (SA); pp. 44-52.

Rall, J. L., Steyn, G. J., Du Preez, H. H., \& Maema, M. (1993). An ecological study on the Maloti minnow (Pseudobarbus quathlambae) in the catchment area of Phase 1B of the Lesotho Highland Water Scheme. Report, Dept of Zoology, Rand Afrikaans University, Aucklandpark.

Schmitz, G., \& Rooyani, F. (1987). Lesotho: Geology, geomorphology, soils. National University of Lesotho, Roma (Lesotho).

Schwabe, C. A. (1990). A preliminary ecological evaluation of the wetlands in Sehlabathebe National Park, Lesotho. Unpublished report. Natal Parks Board, Pietermaritzburg.

Skelton, P. H. (1987). South African Red Data Book - Fishes. South African National Science Programme, Report, 137.

Skelton, P. H. (2001). A complete guide to the freshwater fishes of Southem Africa. Southem Book Publishers, Halfway House.

Visser, J., \& Channing, A. (1997). A new species of river frog from the Swartberg, South Africa. (Ranidae: Afrana). Journal of African Zoology, 111, 191-198. 